\title{
Correction to: Soil microbial biomass phosphorus can serve as an index to reflect soil phosphorus fertility
}

\author{
Yi Peng ${ }^{1}$ - Yisheng Duan ${ }^{1} \cdot$ Weige Huo ${ }^{1} \cdot$ Minggang $\mathrm{Xu}^{2} \cdot$ Xueyun $\mathrm{Yang}^{3} \cdot \mathrm{Xihe} \mathrm{Wang}^{4} \cdot$ Boren Wang $^{2}$. \\ Martin S. A. Blackwell ${ }^{5}$. Gu Feng ${ }^{1}$ (i)
}

Published online: 23 April 2021

๑) Springer-Verlag GmbH Germany, part of Springer Nature 2021

\section{Correction to: Biology and Fertility of Soils https://doi.org/10.1007/s00374-021-01559-z}

In the original published version of this article the first corresponding author should have been Gu Feng and second corresponding author is Minggang $\mathrm{Xu}$.

The original article has been corrected.
Publisher's Note Springer Nature remains neutral with regard to jurisdictional claims in published maps and institutional affiliations.

The original article can be found online at https://doi.org/10.1007/ s00374-021-01559-z.

Minggang Xu

xuminggang@caas.cn

$\bowtie$ Gu Feng

fenggu@cau.edu.cn

1 College of Resources and Environmental Sciences, National Academy of Agriculture Green Development, China Agricultural University, Beijing 100193, China

2 National Engineering Laboratory for Improving Quality of Arable Land, Institute of Agricultural Resources and Regional Planning, Chinese Academy of Agricultural Sciences, Beijing 100081, China

3 Key Laboratory of Plant Nutrition and the Agri-Environment in Northwest China, Ministry of Agriculture, College of Resources and Environment, Northwest A \& F University, Yangling, Xianyang 712100, Shaanxi, China

4 Institute of Soil and Fertilizer and Agricultural Sparing Water, Xinjiang Academy of Agricultural Science, Urumqi 830091, China

5 Sustainable Agriculture Systems, Rothamsted Research, North Wyke EX20 2SB, UK 